\title{
The N-methyl-D-aspartate Antagonist, MK-801, Fails to Protect against Neuronal Damage Caused by Transient, Severe Forebrain Ischemia in Adult Rats
}

\author{
Alastair Buchan, ${ }^{1,2} \mathrm{Hui}_{\mathrm{Li}}{ }^{2}$ and William A. Pulsinelli ${ }^{1}$ \\ 'Cerebrovascular Disease Research Center and The Raymond and Beverly Sackler Foundation, Inc., Department of \\ Neurology and Neuroscience, Cornell University Medical Center, New York, New York 10021 and \\ 'Laboratory of Cerebral Ischemia, Robarts Research Institute, Department Clinical Neurological Sciences, University \\ Hospital, London, Ontario, Canada
}

\begin{abstract}
The neuroprotective effects of dizocilipine maleate (MK-801), a noncompetitive antagonist of the $\mathrm{N}$-methyl-D-aspartate (NMDA) receptor/channel, were tested in the 4-vessel occlusion rat model of forebrain ischemia. Adult Wistar rats, treated intraperitoneally with MK-801 or saline using several different treatment paradigms were subjected to $5(n=208)$ or $15(n=62) \mathrm{min}$ of severe, transient forebrain ischemia. In saline-treated animals, $15 \mathrm{~min}$ of ischemia $(n=13)$ produced extensive and consistent loss of pyramidal neurons in the CA1 zone of hippocampus. The degree and distribution of cell loss were not reduced by single dose preischemic administration of MK-801 at $1(n=7), 2.5(n=4)$, or 5 $\mathrm{mg} / \mathrm{kg}(n=8)$. In other animals subjected to $15 \mathrm{~min}$ of forebrain ischemia, multiple doses of MK-801 (5, 2.5, and 2.5 $\mathrm{mg} / \mathrm{kg}$ ) given immediately and at approximately 8 and $20 \mathrm{hr}$ after cerebral reperfusion $(n=5)$ did not alter CA1 injury compared to saline-treated controls $(n=5)$. Five minutes of forebrain ischemia in saline-treated animals, $(n=82)$ resulted in significantly fewer $(p<0.001)$ dead CA1 pyramidal cells and a greater variance compared to animals subjected to $15 \mathrm{~min}$ of ischemia. Power analysis of the preliminary saline-treated animals subjected to $5 \mathrm{~min}$ of ischemia $(n=$ 22) indicated that 60 animals per group were necessary to detect a $15 \%$ difference between MK- 801 and vehicle-treated groups. Multidose treatment with MK-801 $(1 \mathrm{mg} / \mathrm{kg})$ given $1 \mathrm{hr}$ prior to $5 \mathrm{~min}$ of ischemia $(n=60)$ and again at approximately 8 and $16 \mathrm{hr}$ after recirculation falled to attenuate hippocampal injury. Despite doses of MK-801 that produced marked behavioral abnormalities in the rats, no protection against ischemic injury to CA1 neurons was observed with any of the treatment paradigms. These data fail to support a singular role for the NMDA receptor/channel in the pathogenesis of injury to neurons from even brief periods of severe ischemia.
\end{abstract}

\footnotetext{
Received Aug. 31, 1990; revised Nov. 19, 1990; accepted Nov. 21, 1990.

We thank Drs. Martin Lesser and Allan Donner for their assistance with statistical analysis of the data; Merck, Sharpe, and Dohme supplied the MK-801. Alastair Buchan was supported by a Canadian MRC Centennial Fellowship and grants from the Heart and Stroke Foundation of Ontario. This research was supported by NIH Grant NS-03346.

Correspondence should be addressed to William A. Pulsinelli, M.D., Ph.D. Cerebrovascular Disease Research Center, Department of Neurology and Neuroscience, Cornell University Medical College, 1300 York Avenue, New York, New York 10021.

Copyright (C) 1991 Society for Neuroscience $0270-6474 / 91 / 111049-08 \$ 03.00 / 0$
}

Transient but severe global or forebrain ischemia, which occurs clinically in patients successfully resuscitated from cardiac arrest and experimentally in some animal models, causes irreversible injury to a few, specific populations of highly vulnerable neurons (Spielmeyer, 1925; Brierley, 1976; Brown, 1977). The hippocampal CA1 pyramidal cells are especially sensitive to injury and are prone to die following a few minutes of cerebral ischemia. A unique feature of such injury to this neuronal population is that histological signs of irreversible damage do not appear until 24-48 hr after cerebral recirculation. Why these particular neurons should be so vulnerable to ischemia, and why the onset of histological injury is delayed for approximately $24 \mathrm{hr}$ after the ischemia, remains an enigma-one that has becn dcmonstrated in the rat (Pulsinelli et al., 1982a), the gerbil (Kirino, 1982), and in the human (Petito et al., 1987).

The pathophysiological events underlying the "selective vulnerability" of specific neurons to hypoxia-ischemia is the subject of much research and debate. Recent successes with unraveling some of the mechanisms of excitatory amino acid-mediated injury to neurons using in vitro preparations (Rothman, 1985; Garthwaite and Garthwaite, 1986; Choi, 1987) have stimulated efforts to demonstrate similar cause-effect relationships between excitatory amino acids and neuronal death from ischemia in vivo. The excitatory amino acid neurotransmitters, glutamate and aspartate, known to be neurotoxic in cell cultures (Rothman and Olney, 1986) also cause local cell death when sufficiently high concentrations are injected into brain (Olney, 1978; Mangano and Schwarcz, 1983). Postsynaptic receptors for the excitatory amino acids, particularly those of the $N$-methyl-D-aspartate (NMDA) class, are concentrated in the CAl zone of the hippocampus (Monaghan and Cotman, 1985). Ischemia causes release of glutamate and aspartate (Benveniste et al., 1984; Hagberg et al., 1985), which may then cause lethal excitation of postsynaptic neurons. These observations, plus others, support the hypothesis that an imbalance between excitation and inhibition may partially explain, at a molecular level, the selective vulnerability of specific neurons to ischemia (Meldrum, 1981; Francis and Pulsinelli, 1982; Jorgensen and Diemer, 1982).

The observations that neuroprotection against transient forebrain ischemia obtained by blockade of the NMDA receptor with either local infusions of the competitive antagonist, aminophosphonoheptanoic acid (APH), in the rat (Simon et al., 1984; Swan et al., 1988) or the systemic administration of the noncompetitive antagonist, (+)-5-methyl-10,11-dihydro-5H- 
dibenzo[a,d]cyclohepten-5,10-imine maleate (MK-801), in gerbils (Gill et al., 1987a) and rats (Gill et al., 1987b; Church et al., 1988; Rod and Auer, 1989; Swan and Meldrum, 1990) lend further support to the hypothesis that excitotoxins (Olney, 1978) and the NMDA receptor are uniquely important to the pathogenesis of selective ischemic necrosis of neurons. Hypoxic-ischemic brain injury in neonatal animals has also been successfully treated with MK-801 (McDonald et al., 1987; Olney et al., 1989a). However, several laboratories (Block and Pulsinelli, 1987; Wieloch et al., 1988; Fleischer ct al., 1989; Michenfelder et al., 1989; Lanier et al., 1990) failed to obtain protection of CA1 pyramidal neurons using competitive or noncompetitive NMDA antagonists in animals subjected to transient but severe forebrain ischemia.

The purpose of this study was to examine the basis for the discrepant results and to determine whether single or multiple doses of the potent, noncompetitive NMDA antagonist, MK801 , were effective in attenuating neuronal injury if shorter intervals of severe ischemia were used. The discussion that follows is limited to adult animals since the maturation and sensitivity of the NMDA receptor may be quite different in neonatal animals (Olney et al., 1989a).

\section{Materials and Methods}

4-Vessel occlusion surgery. Male Wistar rats weighing 150-275 gm were used in the experiments. They were maintained on a 12-hr alternating light-and-dark cycle and given free access to food and water. Transient forebrain ischemia was achieved using a modification (Pulsinelli and Duffy, 1983; Pulsinelli and Buchan, 1988) of the 4-vessel occlusion method (Pulsinelli and Brierley, 1979). Animals were anesthetized with a mixture of $2 \%$ halothane, $70 \% \mathrm{~N}_{2}$, and $28 \% \mathrm{O}_{2}$. The carotid arteries were isolated through a midline neck incision, and atraumatic clasps were placed loosely around both common carotid vessels. A silk ligature was passed anterior to the cervical and paravertebral muscles but posterior to the trachea, esophagus, external jugular veins, and common carotid arteries. The incision was then closed with a surgical clip and the ends of the ligature were taped to the nape of the neck.

A second incision was made behind the occipital bone, and the paraspinal muscles were separated to expose the alar foramina. The vertebral arteries were electrocauterized in the alar foramina of the first cervical vertebra. The wound was then sutured and the animals were allowed to recover from anesthesia overnight. Postoperatively, water was provided but food was withheld.

On the day of the experiment, the ventral neck wound was injected with lidocaine $(1 \%)$ and the wound clip was removed. The common carotid arteries were occluded first and then the ligature encircling the paravertebral muscles was tightened in the awake rat. Animals that did not fully lose their righting reflexes following carotid artery occlusion were excluded from further study. Because loss of the righting reflex is the principal criteria for assuring severe forebrain ischemia in the 4-vessel rat model (Pulsinelli et al., 1982b; Pulsinelli and Buchan, 1988), and because high-dose $(5-10 \mathrm{mg} / \mathrm{kg}$ ) MK-801-treated animals were already lethargic (see below), great care was necessary to assure that the latter animals were subjected to an equivalently severe degree of ischemia compared to vehicle-treated rats. Accordingly, animals were excluded from the study unless they developed fully dilated pupils in addition to loss of the righting reflex upon tightening the carotid artery and neck ligatures. Assuring equivalent degrees of cerebral ischemia between control- and MK-801-treated animals was less problematic in the 15-min ischemic group treated with multiple doses of MK-801 (see below) because the animals received their first dose of MK-801 immediately after release of the carotid artery clasps.

At the end of either 5 or $15 \mathrm{~min}$ of ischemia, the animals were reexamined for their ability to right and for the presence of dilated pupils; those able to right or animals with pinpoint pupils were classified as noncriteria and were excluded. The carotid artery clasps were then released, and restoration of carotid artery blood flow was checked by direct observation of the vessels. Core body temperature in all animals was maintained at a minimum of $37.5 \pm 0.5^{\circ} \mathrm{C}$ with a rectal thermistor
(Yellow Springs, Inc.) and heating lamp during the ischemic insult and during the postischemic period until the animals regained the ability to maintain thermal homeostasis several hours later.

Experimental paradigms. In the single-dose treatment paradigms animals subjected to either 5 or $15 \mathrm{~min}$ of ischemia received an intraperitoneal (i.p.) injection of MK-801 at doses of $0.3,1,2.5,5$, or $10 \mathrm{mg}$ / $\mathrm{kg} 1 \mathrm{hr}$ prior to the onset of forebrain ischemia. Control animals were administered saline $(0.1 \mathrm{ml} / 100 \mathrm{gm}, \mathrm{i} . \mathrm{p}) .1 \mathrm{hr}$ prior to the ischemic insult.

In the multiple-dose treatment paradigms MK-801 or saline was given immediately after $(5 \mathrm{mg} / \mathrm{kg}$, i.p.) and again at approximately 8 and 20 $\mathrm{hr}(2.5 \mathrm{mg} / \mathrm{kg})$ after $15 \mathrm{~min}$ of forebrain ischemia. In separate studies, animals subjected to $5 \mathrm{~min}$ of ischemia were injected with MK-801 1 $\mathrm{hr}$ prior to carotid artery occlusion and again at approximately 8 and $16 \mathrm{hr}$ after cerebral recirculation.

Histological injury from the initial 5 -min ischemic animals treated with MK-801 or saline varied considerably compared to the $15-\mathrm{min}$ ischemic animals (see below). To minimize the risk of a Type II statistical error, an additional series of rats were subjected to $5 \mathrm{~min}$ of ischemia and treatment with multiple doses of MK-801 $(1 \mathrm{mg} / \mathrm{kg} \times 3, n=$ 78 ) or saline $(n=73)$ at the above time intervals.

Physiologic monitoring. Mean arterial blood pressure, arterial oxygen and carbon dioxide partial pressures, $\mathrm{pH}$, and plasma glucose concentrations were measured serially in separate animals prior to saline or MK-801 therapy, 60-90 min after such treatment, during forebrain ischemia, and $1 \mathrm{hr}$ after cerebral reperfusion. Tail artery cannulae were inserted in halothane anesthetized rats that were surgically prepared for 4-vessel occlusion $24 \mathrm{hr}$ earlier. Physiologic measurements were taken after the animals were allowed $3-4$ hr to recover from halothane anesthesia.

Twelve animals were entered in this phase of the study. One salinetreated animal died during 4-vessel occlusion and, in another, the arterial cannula failed to provide an adequate pulse pressure for accurate blood pressure measurements. However, in the latter animal, sufficient blood could be collected for the measurement of the remaining physiologic variables. Two of $6 \mathrm{MK}-801$-treated rats were injected with 5 $\mathrm{mg} / \mathrm{kg}$, i.p., and the remaining 4 animals received a dose of $1 \mathrm{mg} / \mathrm{kg}$, i.p. Saline $(0.1 \mathrm{ml})$ was administered intraperitoneally to the control animals. Histopathology was not assessed in these animals.

Neuropathologic analysis. Three to seven days after cerebral recirculation the animals were reanesthetized and their brains were perfusion-fixed with FAM (40\% formaldehyde : glacial acetic acid : methanol, $1: 1: 8)$ via the ascending aorta. The cephalic circulation was washed briefly with heparinized physiologic saline prior to perfusion with FAM. The brains were left in situ at $4^{\circ} \mathrm{C}$ overnight. Coronal sections, $7-\mu \mathrm{m}$ thick of paraffin embedded brain, were cut at several levels of the dorsal hippocampus and stained with hematoxylin and eosin.

Ischemic neuronal damage to the left and right hippocampus of all animals treated with saline or MK-801 was quantified with the light microscope by observers blinded to the experimental conditions. Hippocampal damage was assessed by counting the number of histologically normal appearing CAl neurons. Sections from at least 2 different coronal levels of dorsal hippocampus from each animal were examined. Irreversible ischemic damage was accepted in any neuron showing a shrunken appearance with eosinophilic cytoplasm and a dark, pyknotic staining nuclei, or in neurons that had progressed to "homogenizing changes" or a "naked nuclei" (Brierley, 1976; Brown, 1977). Neurons without such changes were classified as normal. The results were expressed as the percentage of dead neurons by subtracting the number of normal CAl neurons from the total $\mathrm{CA} 1$ neurons per coronal section and dividing by the total cell count. The total number of CAl neurons in $7-\mu \mathrm{m}$ thick sections, representative of the same coronal levels used in the ischemic animals, were counted in 6 normal rats with the light microscope.

Statistical analysis. Selection of the most appropriate statistical method (i.e., parametric versus nonparametric) to analyze these data is complicated by the fact that percentage data are not normally distributed by nature (Zar, 1974), and the presence of unequal variances between some of the groups. Because parametric analysis theory is based on normally distributed populations with equal variances (Zar, 1974), most statistical textbooks (Zar, 1974; Armitage and Berry, 1987) recommend the use of nonparametric methods when either or both of these population characteristics are seriously violated. However, nonparametric analysis is somewhat less powerful than parametric methods and slightly increases the risk of introducing a Type II error, i.e., concluding that 
Table 1. Number of animals subjected to $15 \mathrm{~min}$ of ischemia

\begin{tabular}{lrrrrrrr} 
& \multicolumn{7}{l}{ Treatment groups MK-801 (mg/kg) } \\
\cline { 3 - 6 } & Saline & 1 & 2.5 & 5 & 10 & $\begin{array}{l}\text { Multi- } \\
\text { dose }\end{array}$ & Totals \\
\hline Entered & 14 & 10 & 8 & 18 & 6 & 6 & 62 \\
Noncriteria & 1 & 1 & 2 & 3 & 0 & 0 & 7 \\
Died & 0 & 2 & 2 & 7 & 6 & 1 & 18 \\
Available for histology & 13 & 7 & 4 & 8 & 0 & 5 & 37 \\
\hline
\end{tabular}

no difference exists between groups when in fact one does. Efforts to normalize the distribution of our data with either arcsine (Zar, 1974) or logit (Armitage and Berry, 1987) transformations were successful for only 3 (15-min ischemia treated with either single- or multidose MK801 ; 5-min ischemia treated with $0.3 \mathrm{mg} \times 3 \mathrm{MK}-801$ ) of the 6 separate study groups. Accordingly, we elected to analyze the results with both parametric and nonparametric methods, and to report significant differences obtained with either analysis at the $\alpha=0.05$ level.

Data from the single-dose MK-801 treatment paradigms (see Table 4) in which multiple treatment groups were tested against a single salinetreated control group were transformed to their arcsine and logit values and the latter were examined by analysis of variance and the Dunnett test for multiple comparisons. Nonparametric analysis on the untransformed data from the same studies was performed with the KruskalWallis test; multiple comparisons were made with the Mann-Whitney $U$ test using a Bonferroni correction.

Parametric analysis of the multiple-dose MK-801 treatment paradigms (see Table 5) was performed on the arcsine- and logit-transformed data using the 2-tailed Student's $t$ test. The nontransformed values for thesc same data were analyzed nonparametrically with the Mann-Whitney $U$ test.

The differences between saline-treated control animals subjected to either 5 or $15 \mathrm{~min}$ of ischemia were tested for significance with the Mann-Whitney $U$ test. Student's $t$ test for unpaired data was used to analyze differences in the physiological variance.

The risk of a Type II statistical error for the $15-\mathrm{min}$ ischemia animals was analyzed post hoc with $\alpha=0.05$ and $\beta=0.80$ (Cohen, 1977). $A$ priori power analysis with the above $\alpha$ and $\beta$ values was used to determine the number of 5 -min ischemia animals necessary to detect a $15 \%$ difference between MK-801 and saline treatment. We used the initial 22 animals subjected to $5 \mathrm{~min}$ of ischemia and saline treatment for the latter analysis. A $15 \%$ reduction in the number of dead CA1 neurons was selected as a target difference since this represents the minimum protection previously reportcd with NMDA antagonist therapy in global ischemia models (Buchan, 1990). The results indicated that 60 animals per group were required.

\section{Results}

All animals given MK-801 were behaviorally affected in a dosedependent manner. Initial hyperactivity, stereotypy, and ataxia were followed by motor retardation, pupillary constriction, tremors, and salivation. At the $5-$ and $10-\mathrm{mg} / \mathrm{kg}$ doses, many of the animals were unable to right when placed on their sides.
The combination of 4-vessel occlusion and MK-801 resulted in a high mortality from respiratory failure, especially in the 5and $10-\mathrm{mg} / \mathrm{kg}$ groups.

The numbers of animals entered into each of the studies and the final numbers available for histological analysis are summarized in Tables 1 and 2. The major cause of mortality in the MK-801-treated animals was neurogenic pulmonary edema which developed during forebrain ischemia; of 6 animals treated with $10 \mathrm{mg} / \mathrm{kg}$, none survived the ischemic insult (Table 1).

Physiologic endpoint measures showed few significant differences between saline- and MK-801-treated animals (Table 3). Treatment with MK-801 caused slight respiratory depression which was manifested prior to and after forebrain ischemia by mild hypercarbic acidosis. With the exception of the mean arterial blood pressure, physiologic variables were not different for the $5-\mathrm{mg} / \mathrm{kg}$ - versus $1-\mathrm{mg} / \mathrm{kg}$-treated animals; values other than the blood pressure for these animals were therefore pooled. Mean arterial pressure at $60-90 \mathrm{~min}$ after the $5-\mathrm{mg} / \mathrm{kg} \mathrm{MK}-801$ dose was 123 and 132 Torr in the 2 animals so treated. These values were excluded from the analysis of blood pressure at this time point. Body temperature in the MK-801-treated animals during and following forebrain ischemia was significantly $(p<$ 0.05 ) lower than the saline-treated animals. As described in Materials and Methods, body temperature was monitored and never allowed to fall below $37.5 \pm 0.5^{\circ} \mathrm{C}$ in any of the animals. As previously reported in this model (Pulsinelli and Brierley, 1979), forebrain ischemia caused an increase in arterial blood pressure, a rise in plasma glucose, hypcroxia, and hypocarbic alkalosis secondary to central hyperventilation.

The mean \pm SD percentages of dead CA1 hippocampal neurons for all treatment groups are summarized in Tables 4 and 5. In the single-dose pretreatment paradigms (Table 4, Fig. 1), hippocampal damage in animals subjected to $15 \mathrm{~min}$ of ischemia (Fig. 1) and 5-mg/kg MK-801 therapy was slightly but significantly $(p<0.05)$ greater than the saline-treated controls. Five minutes of ischemia caused significantly less $(p<0.001)$ and more variable damage compared to animals exposed to $15 \mathrm{~min}$

Table 2. Number of animals subjected to $5 \mathrm{~min}$ of ischemia

\begin{tabular}{|c|c|c|c|c|c|c|c|}
\hline & \multirow{3}{*}{$\begin{array}{l}\text { All } \\
\text { saline }\end{array}$} & \multicolumn{5}{|c|}{ Treatment groups MK- $801(\mathrm{mg} / \mathrm{kg})$} & \multirow[b]{3}{*}{ Totals } \\
\hline & & \multicolumn{2}{|c|}{ Single dose } & \multicolumn{3}{|c|}{ Multidose } & \\
\hline & & 0.3 & 1 & $0.3 \times 3$ & $5,2.5,2.5$ & $1.0 \times 3$ & \\
\hline Entered & 101 & 7 & 10 & 6 & 6 & 78 & 208 \\
\hline Noncriteria & 10 & 0 & 0 & 0 & 0 & 7 & 17 \\
\hline Died & 9 & 1 & 2 & 0 & 1 & 11 & 24 \\
\hline Available for histology & 82 & 6 & 8 & 6 & 5 & 60 & 167 \\
\hline
\end{tabular}


Figure 1. Percentage of CA1 pyramidal neurons with irreversible damage after single-dose MK-801 therapy and 15 min of forebrain ischemia. The open and filled circles represent the percentage of dead cells in the left and right hippocampi, respectively, of each animal. The squares with error bars represent the means \pm SD for each group. Asterisk denotes significantly greater injury at the $p<0.05$ level compared to the saline-treated group.

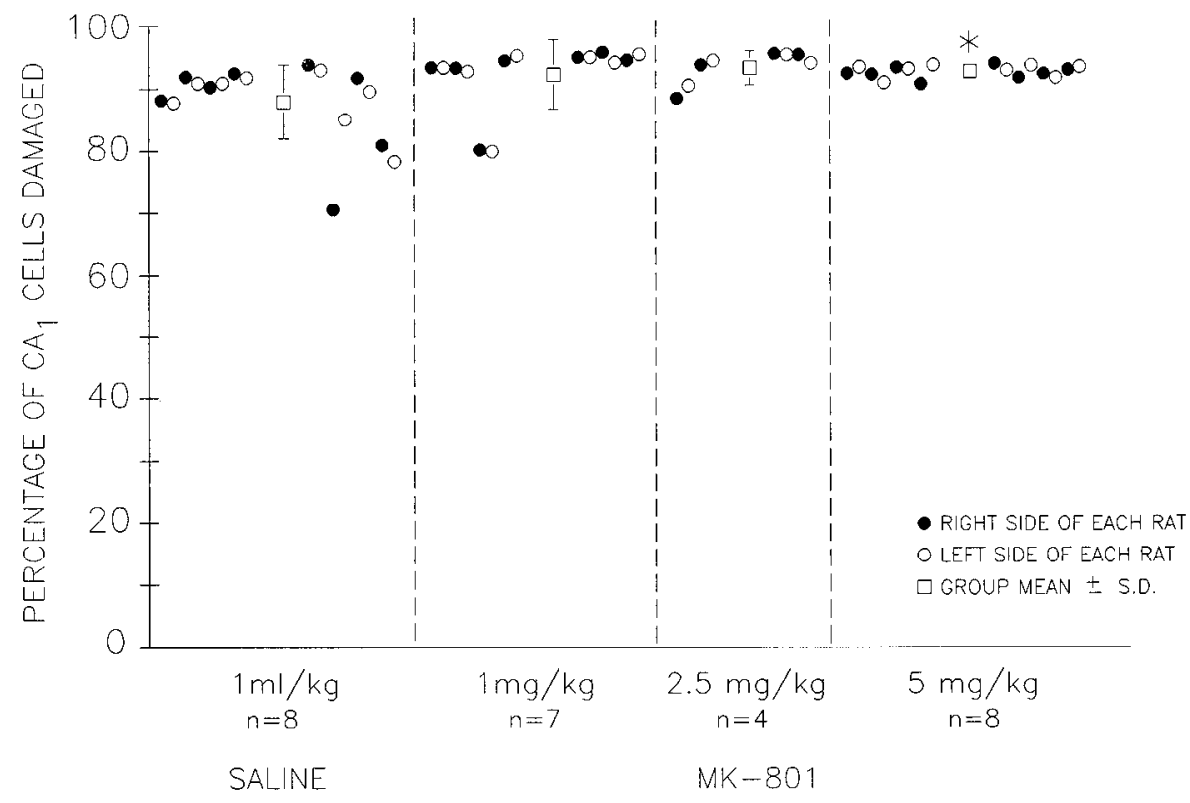

of ischemia. No attenuation of injury was detected in any of the MK-801 treatment groups. Post hoc power analysis of the 15min ischemia data indicated we would have detected a difference as little as $7 \%$ between treatment groups had one existed.

In the multidose treatment paradigms (Table 5, Fig. 2) no significant differences were observed between any of the MK801 - and saline-treated groups. One saline-treated animal in the 15 min ischemia group suffered injury to only $10 \%$ of its CAl neurons. This animal was excluded from the mean value presented in Table 5 but analysis of the data for significant differences was not altered by inclusion or exclusion of this animal. Post hoc power analysis of the 15-min ischemia multidose data indicated that we would have detected a difference of $12 \%$ or greater between MK-801- versus the saline-treated groups. The variance of the 5-min ischemia animals was once again considerably greater than their 15 -min counterparts. Power analysis of all initial 5-min ischemia animals treated with saline ( $n=$ 22) indicated that at $\alpha=0.05$ and $\beta=0.80,60$ animals in the MK-801 and control groups would be necessary to detect a difference of $15 \%$ or greater between groups. The results of the latter study indicate that multiple $1-\mathrm{mg} / \mathrm{kg}$ doses of MK-801 fail to protect $85 \%$ of CAl neurons following $5 \mathrm{~min}$ of ischemia.

\section{Discussion}

The excitotoxin hypothesis (Olney, 1978), which altributes neurotoxic properties to some amino acid neurotransmitters in proportion to their ability to excite neurons, has been embraced by the neurological community to help explain CNS injury from epilepsy, degenerative diseases, trauma, and hypoxia-ischemia (Rothman and Olney, 1986; Cotman and Iversen, 1987). Moreover, the identification of pharmacological agents that block excitatory amino acid neurotransmitter receptors, particularly those affecting the NMDA receptor and its voltage-modulated channel, has stimulated efforts to develop new therapies to lessen brain damage from stroke and cardiac arrest.

Our failure in this study to observe neuroprotection against forebrain ischemia by blockade of the NMDA receptor/channel complex cannot be attributed to inadequate receptor antagonist dosage, extraordinarily severe ischemic conditions, or lack of experience with the animal model. We chose one of the most

Table 3. Physiological variables

\begin{tabular}{|c|c|c|c|c|c|c|c|c|c|c|c|c|}
\hline & \multicolumn{2}{|c|}{$\begin{array}{l}\text { Mean art pres } \\
\text { (Torr) }\end{array}$} & \multicolumn{2}{|c|}{$\mathrm{PO}_{2}$ (Torr) } & \multicolumn{2}{|c|}{$\mathrm{PCO}_{2}$ (Torr) } & \multicolumn{2}{|l|}{$\mathrm{pH}$} & \multicolumn{2}{|c|}{ Glucose } & \multicolumn{2}{|c|}{ Temp $\left({ }^{\circ} \mathrm{C}\right)$} \\
\hline & $\overline{\mathrm{VEH}}$ & MK & VEH & MK & VEH & MK & VEH & MK & VEH & MK & VEH & MK \\
\hline \multirow[t]{2}{*}{ Prior to $\mathrm{Rx}$} & 109.0 & 112.7 & 81.5 & 84.5 & 38.8 & 39.4 & 7.43 & 7.40 & 139.4 & 132.0 & 38.7 & 38.5 \\
\hline & $(7.8)$ & $(4.0)$ & $(4.2)$ & $(5.1)$ & $(2.3)$ & $(3.4)$ & $(0.02)$ & $(0.03)$ & $(21.6)$ & (13.3) & $(0.4)$ & $(0.5)$ \\
\hline \multirow{2}{*}{$\begin{array}{l}\text { Post-Rx } \\
\qquad(60-90 \mathrm{~min})\end{array}$} & 100.5 & 111.8 & 82.7 & 86.0 & 37.8 & $43.0^{* *}$ & 7.44 & $7.36^{*}$ & 134.8 & 150.7 & 38.5 & 37.9 \\
\hline & $(8.2)$ & $(12.8)$ & $(4.0)$ & (7.2) & (2.6) & $(4.2)$ & $(0.02)$ & $(0.05)$ & $(30.5)$ & $(23.5)$ & $(0.9)$ & $(0.9)$ \\
\hline \multirow[t]{2}{*}{ During ischemia } & 137.8 & 137.0 & 100.5 & 109.6 & 27.3 & 28.5 & 7.53 & 7.50 & 190.4 & 180.0 & 38.6 & $37.6^{* *}$ \\
\hline & $(5.4)$ & $(12.3)$ & (12.1) & $(15.8)$ & $(8.0)$ & $(7.9)$ & $(0.09)$ & $(0.08)$ & $(19.7)$ & $(34.6)$ & $(0.8)$ & $(0.4)$ \\
\hline \multirow{2}{*}{$\begin{array}{l}\text { Postischemia } \\
\text { (60 min) }\end{array}$} & 112.5 & 105.0 & 92.3 & 84.9 & 38.4 & 42.2 & 7.43 & $7.37^{* *}$ & 202.4 & 203.8 & 38.3 & $37.5^{* *}$ \\
\hline & $(5.3)$ & $(4.0)$ & (4.9) & (8.5) & (5.1) & (3.2) & $(0.03)$ & $(0.05)$ & $(35.8)$ & $(69.9)$ & $(0.5)$ & $(0.5)$ \\
\hline
\end{tabular}

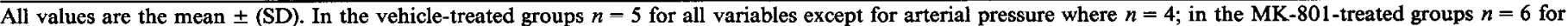

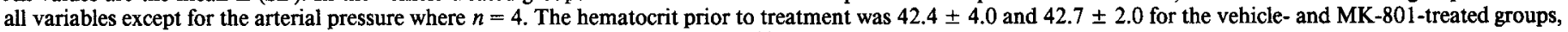
respectively. Significantly different from the vehicle-treated group at ${ }^{*} p<0.01,{ }^{* *} p<0.05$. 
Table 4. Mean \pm SD percentage of dead CA1 neurons (single-dose MK-801)

\begin{tabular}{llllll} 
& \multicolumn{5}{l}{ MK-801 (mg/kg) } \\
\cline { 2 - 5 } & Saline & 0.3 & 1 & 2.5 & 5 \\
\hline 15-min isch. & $88 \pm 6$ & & $92 \pm 5$ & $93 \pm 3$ & $93 \pm 1^{*}$ \\
& $(8)$ & & $(7)$ & $(4)$ & $(8)$ \\
5-min isch. & $41 \pm 25^{* *}$ & $27 \pm 28$ & $57 \pm 29$ & & \\
& $(11)$ & $(6)$ & $(8)$ & & \\
\hline
\end{tabular}

Values in parentheses equal $n$.

${ }^{*} p<0.05$ compared to $15 \mathrm{~min}$ saline, (Kruskal-Wallis, Mann-Whitney $U$ plus Bonferroni correction).

${ }^{* *} p<0.001$ compared to $15 \mathrm{~min}$ saline (Mann-Whitney $U$ test).

potent NMDA receptor/channel antagonists available, MK-801, and spanned the dose range reported by others (Gill et al., 1987a,b; Church et al., 1988; Rod and Auer, 1989; Swan and Meldrum, 1990) to provide neuroprotection against forebrain ischemia.

The particular rat model of transient forebrain ischemia used in this study was developed by us (Pulsinelli and Brierley, 1979; Pulsinelli and Duffy, 1983) and it has been used extensively (Pulsinelli et al., 1982a,b; Buchan and Pulsinelli, 1990a) for over 10 years. This model has been adopted and modified by other laboratories to meet a variety of needs. Consequently, it has been exceptionally well characterized from the standpoint of the temporal development of the histopathology (Pulsinelli et al., 1982a; Kirino et al., 1984) and the severity and reproducibility of forebrain ischemia (Ginsberg, 1981; Pulsinelli et al., 1982b; Todd et al., 1986; Schmidt-Kastner et al., 1989). In this particular study we reduced the ischemic interval from 30 to $15 \mathrm{~min}$, and finally to $5 \mathrm{~min}$, to assure a submaximal insult as judged by the percentage of CA1 neurons killed. Despite such efforts to maximize the potential effect of NMDA receptor/channel blockade, we observed no protection with MK-801 therapy.

The results of our study are consistent with other reports that MK-801 failed to alter the histopathologic or behavioral outcomes of rats (Wicloch ct al., 1988), cats (Flcischcr ct al., 1989), dogs (Michenfelder et al., 1989), or primates (Lanier et al., 1990) subjected either to transient forebrain or global ischemia. In addition, no change in the histopathology of CA1 hippocampus was observed in rats subjected to forebrain ischemia and treatment either with the competitive antagonist, APH (Block and Pulsinelli, 1987; Jensen and Auer, 1989), or the noncompetitive antagonist, ketamine (Church et al., 1988; Jensen and Auer, 1988).

These negative studies contrast with those where protection against forebrain ischemia in rodents treated with competitive or noncompetitive NMDA receptor antagonists was found. Simon et al. (1984) reported approximately $37 \%$ reduction of injury to CA1 hippocampus of 4 rats subjected to $30 \mathrm{~min}$ of forebrain ischemia and intrahippocampal infusions of APH. More recent studies from the same laboratory, using only 10 min of ischemia in rats, revealed a $21 \%$ reduction of CA 1 damage in the APH versus vehicle-treated hippocampi (Swan et al., 1988). Other studies in the rat have also noted protection against transient forebrain ischemia with the noncompetitive NMDA antagonists, MK-801 (Gill et al., 1987b; Church et al., 1988; Rod and Auer, 1989; Swan and Meldrum, 1990), or phencyclidine (Sauer et al., 1988).

In gerbils, remarkable degrees of protection against ischemic injury to hippocampal neurons have been reported for the com- petitive NMDA antagonists, cis-4-(phosphonomethyl)-2-piperidine-carboxylic acid (CGS) and 4-(3-phosphonopropyl)-2-piperazine-carboxylic acid (CPP; Boast et al., 1988) and for the noncompetitive antagonists, MK-801 (Gill et al., 1987a) and ketamine (Marcoux et al., 1988). MK-801 was found to be highly effective at preventing hippocampal cell loss at doses ranging from $0.1 \mathrm{mg} / \mathrm{kg}$ to $10 \mathrm{mg} / \mathrm{kg}$, i.p., when given $1 \mathrm{hr}$ prior to ischemia.

In contrast to the discrepant data concerning NMDA receptor blockade in global or forebrain ischemia, there is a consensus that antagonists of this receptor/channel complex effectively reduce infarct volume in focal cerebral ischemia. Noncompetitive NMDA antagonist therapy in rats (Germano et al., 1987; Park et al., 1988), cats (Ozyurt et al., 1988), and rabbits (Steinberg et al., 1988) given before or immediately after focal ischemia significantly reduced the volume of cerebral infarction. The identical batch of MK-801 that failed to protect against global brain ischemia in this study was effective in reducing infarct volumes in spontaneously hypertensive rats (SHR; Dirnagl et al., 1990) and Wistar rats (Buchan et al., 1989) subjected to focal cerebral ischemia.

These conflicting data regarding the effects of NMDA antagonism (i.e., in global/forebrain ischemia where the benefit of these compounds is controversial, and in focal ischemia where there is general agreement as to their efficacy) can largely be explained by considering 3 important variables which affect the histopathological outcome.

The duration and magnitude of cerebral blood flow reduction (i.e., the severity of ischemia and the time required for maturation of histological injury) are 2 variables that largely determine the nature, degree, and distribution of brain tissue injury.

\begin{tabular}{|c|c|c|c|c|}
\hline & \multirow[b]{2}{*}{ Saline } & \multicolumn{3}{|c|}{$\mathrm{MK}-801(\mathrm{mg} / \mathrm{kg})$} \\
\hline & & $0.3 \times 3$ & $5,2.5,2.5$ & $1.0 \times 3$ \\
\hline 15-min isch. & $\begin{array}{c}97 \pm 1 \\
(4)\end{array}$ & & $\begin{array}{l}93 \pm 4 \\
(5)\end{array}$ & \\
\hline \multirow[t]{3}{*}{5 -min isch. } & $\begin{array}{c}39 \pm 29 \\
(6)\end{array}$ & $\begin{array}{l}53 \pm 33 \\
(6)\end{array}$ & & \\
\hline & $\begin{array}{c}62 \pm 33 \\
(5)\end{array}$ & & $\begin{array}{l}60 \pm 29 \\
(5)\end{array}$ & \\
\hline & $\begin{array}{l}30 \pm 31 \\
(60)\end{array}$ & & & $\begin{array}{l}36 \pm 32 \\
(60)\end{array}$ \\
\hline
\end{tabular}

\footnotetext{
Values in parentheses equal $n$.
} 
Figure 2. Percentage of CA1 pyramidal neurons with irreversible damage after multiple-dose MK-801 (1 mg/kg $\times 3$ ) therapy and $5 \mathrm{~min}$ of forebrain ischemia. The open circles represent the average percentage of dead cells in the left and right hippocampi of each animal. The filled circles with error bars represent the mean \pm SD for each group.

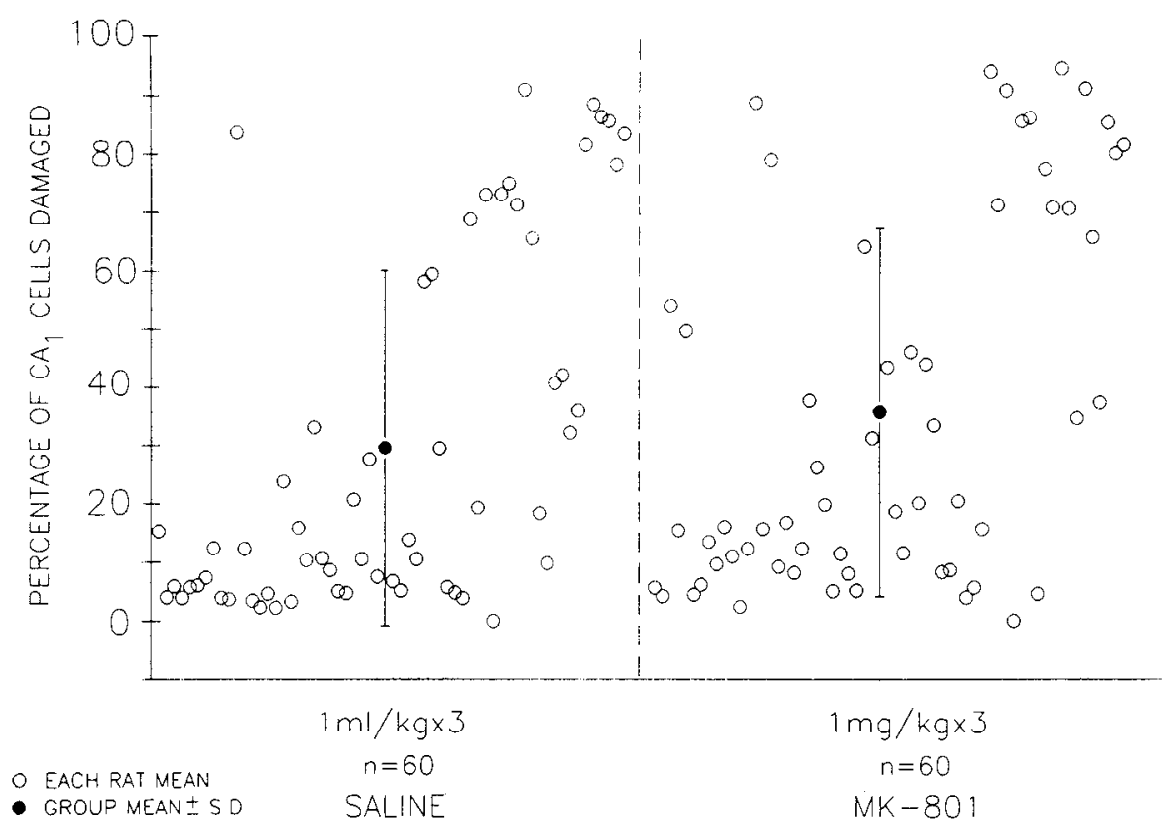

brain injury from focal ischemia, one possible explanation for the neuroprotective effects of NMDA antagonists reported by some laboratories for global/forebrain ischemia really reflects a less-than-expected reduction of blood flow coupled with the ability of NMDA antagonists to protect against moderate but not severe ischemia. Unfortunately no other studies reporting protection with NMDA antagonists measured cerebral blood flow during the ischemic insult. The presence of an isoelectric EEG in some studies showing neuroprotection with NMDA antagonists (Swan et al., 1988; Sauer et al., 1988) is not an adequate index of the severity of ischemia. In our experience the EEG, monitored with surface electrodes, may be isoelectric when electrophysiological activity, and therefore considerable blood flow, remains in the underlying hippocampus.

Brain temperature during the ischemic insult and during the early hours following cerebral reperfusion is the third important factor affecting the histopathological outcome. Busto et al. (1987, 1989) have shown that a $2-4^{\circ} \mathrm{C}$ decline of brain temperature during or following transient forebrain ischemia in rats significantly attenuates ischemic necrosis of neurons. The combination of MK-801 and transient forebrain ischemia in gerbils causes a $2-3^{\circ} \mathrm{C}$ decline in mean body temperature, which lasts for many hours. If body temperature is maintained equally in the MK-801- and saline-treated gerbils during and after forebrain ischemia, then the neuroprotective effect observed with MK801 therapy under ambient temperature conditions is lost (Buchan and Pulsinelli, 1990b; Corbett et al., 1990).

Most of the studies reporting protection by the NMDA antagonists, especially those in gerbils (Gill et al., 1987a; Boast et al., 1988; Marcoux et al., 1988; Rod and Auer, 1989), neither maintained nor monitored body temperature. In others where body temperature was monitored (Church et al., 1988; Sauer et al., 1988; Swan et al., 1988), it is unclear whether normothermia was maintained equally in the vehicle- versus the drug-treated groups throughout both the ischemic and recirculation periods. We suggest that much but not all of the neuroprotection reported with these compounds in global brain ischemia is related to mild hypothermia. 
Is it possible that a neuroprotective response to MK-801 in our study was overshadowed by neurotoxic properties of the NMDA antagonists at higher doses? Reversible vacuolization of cingulate and retrosplenial neurons at doses of MK-801 $<2.5$ $\mathrm{mg} / \mathrm{kg}$ (Olney et al., 1989b, 1990; Allen and Iversen, 1990) and the necrosis of these same neurons at MK-801 doses of $5 \mathrm{mg}$ ' $\mathrm{kg}$ or greater (Allen and Iversen, 1990) were never observed in other brain regions (Olney et al., 1989b, 1990; Allen and Iversen, 1990). Since our histopathological analysis focused on the hippocampus and the bulk of our data came from animals treated with MK-801 doses of $2.5 \mathrm{mg} / \mathrm{kg}$ or less, we believe that the neurotoxic potential of MK-801 did not confound the results of our study. The mortality seen with higher doses of MK-801 in our study resulted from acute respiratory failure occurring within minutes of the onsct of ischemia and was not related to the slow degeneration of neurons over several days.

In summary, this study has attempted to replicate the observations that MK-801 protects hippocampal CA1 cells against transient but severe forebrain ischemia. Despite using relatively brief periods of ischemia, a well characterized model of transient forebrain ischemia, and several treatment paradigms of MK801 spanning a dose range of $0.3-5.0 \mathrm{mg} / \mathrm{kg}$, we found no protective effect of this drug. We suggest that our failure to observe neuroprotection with MK-801 therapy reflects our maintenance of uniformly severe ischemia and normal body/brain temperatures in both the vehicle- and MK-801-treated animals.

We conclude that while the NMDA receptor/channel may be involved in mechanisms leading to brain injury from the conditions characterized by moderate blood flow reduction, and typical of those seen in focal cerebral ischemia, blockade of the NMDA receptor/channcl during or after severe ischemia fails to protect against delayed injury to selectively vulnerable CA1 hippocampal neurons. Moreover, because MK-801 is such a potent and relatively selective antagonist of the NMDA receptor/channel, the results weaken the hypothesis that excitatory amino acids play a singular role in mechanisms causing selective necrosis of neurons following circulatory arrest and severe global ischemia. We suggest that NMDA receptor/channel antagonists will not prove effective in reducing brain damage in patients following transient cardiac arrest.

\section{References}

Allen H, Iversen L (1990) Phencyclidine, dizocilpine, and cerebrocortical neurons. Science 247:221.

Armitage P, Berry G (1987) Distribution-free methods. In: Statistical methods in medical research, second ed, pp 408-409. Oxford: Blackwell Scientific.

Bell BA, Symon L, Branston NM (1985) CBF and time thresholds for the formation of ischemic cerebral edema and the effects of reperfusion in baboons. J Neurosurg 62:31-46.

Benveniste H, Drejer J, Schousboe A, Diemer N (1984) Elevation of extracellular concentrations of glutamate and aspartate in rat hippocampus during transient cerebral ischemia monitored by intracerebral microdialysis. J Neurochem 43:1369-1374.

Block G, Pulsinelli W (1987) $N$-methyl-D-aspartate receptor antagonists: failure to prevent ischemia-induced selective neuronal damage. In: Cerebrovascular diseases, Fifteenth Princeton Conference, (Raichle M, Powers W, eds) pp 37-42, New York: Raven.

Boast C, Gerhardt S, Pastor G, Lehmann J, Etienne P, Liebman J (1988) The $N$-methyl-D-aspartate antagonist CGS 19755 and CPP reduce ischemic brain damage in gerbils. Brain Res 442:345-348.

Brierley J (1976) Cerebral hypoxia. In: Greenfield's neuropathology (Blackwood W, Corsellis J, eds), pp 43-85. London: Edward Arnold Publishers.

Brint S, Jacewicz M, Kiessling M, Tanabe J, Pulsinelli W (1988) Focal brain ischemia in the rat: methods for reproducible infarction using tandem occlusion of the distal middle cerebral and ipsilateral common carotid arteries. J Cereb Blood Flow Metab 8:474-485.

Brown AW (1977) Structural abnormalities in neurons. J Clin Pathol Suppl 30:155-169.

Buchan A (1990) Do NMDA antagonists protect against cerebral ischcmia: are clinical trials warranted? Cerebrovas Brain Metab Rev 2: $1-26$.

Buchan A, Pulsinelli W (1990a) Septo-hippocampal deafferentation protects CA1 neurons against ischemic injury. Brain Res 512:7-14.

Buchan A, Pulsinelli W (1990b) Hypothermia but not the $N$-methylD-aspartate receptor antagonist, MK-801, attenuates neuronal damage in gerbils subjected to transient global ischemia. $\mathbf{J}$ Neurosci 10 : 311-316.

Buchan A, Xue D, Slivka A, Zhang C, Hamilton J, Gelb A (1989) MK-801 increases cerebral blood flow in a rat model of temporary focal cortical ischemia. Soc Neurosci Abst 15:804.

Busto R, Dietrich W, Mordecai G, Valdes I, Scheinberg P, Ginsberg M (1987) Small differences in intraischemic brain temperature critically determines the extent of neuronal injury. J Cereb Blood Flow Metab 7:729-738.

Busto R, Dietrich WD, Mordecai Y, Globus T, Ginsberg M (1989) Postischemic moderate hypothermia inhibits CA1 hippocampal ischemic neuronal injury. Neurosci Lett 101:299-304.

Choi DW (1987) Ionic dependence of glutamate neurotoxicity. J Neurosci 7:369-379.

Church J, Zeeman S, Lodge D (1988) Ketamine and MK-801 as neuroprotective agents in cerebral ischemia/hypoxia. In: Sigma and phencylidine-like compounds as molecular probes in biology. (Domino E, Kamenka J-M, eds), pp. 747-756. Ann Arbor: NPP.

Cohen J (1977) Statistical power analysis for the behavioral sciences. London: Academic.

Corbett D, Evans S, Thomas C, Wang D, Jonas R (1990) MK-801 reduces cerebral ischemic injury by inducing hypothermia. Brain Res 514:300-304.

Cotman C, Iversen L (1987) Excitatory amino acids in the brain: focus on NMDA receptors. Trends Neurosci 10:263-265.

Dirnagl U, Tanabe J, Pulsinelli W (1990) Pre- and posttreatment with MK-801 but not pretreatment alone reduces neocortical damage after focal cerebral ischemia in the rat. Brain Res, in press.

Fleischer J, Tateishi A, Drummond C, Scheller M, Grafe M, Zornow M, Shearman G, Shapiro H (1989) MK-801, an excitatory amino acid antagonist, does not improve neurologic outcome following cardiac arrest in cats. J Cereb Blood Flow Metab 9:805-811.

Francis A, Pulsinelli W (1982) Response of GABAergic and cholinergic neurons to transient forebrain ischemia. Brain Res 243:271278.

Garcia J, Kalimo H, Kamijyo Y, Trump B (1977) Cellular events during partial ccrcbral ischemia. Virchows Arch 25:191-206.

Garthwaite G, Garthwaite J (1986) Neurotoxicity of excitatory amino acid receptor agonists in rat cerebellar slices: dependence on calcium concentration. Neurosci Lett 66:193-198.

Germano IM, Pitts LH, Meldrum BS, Bartkowski HM, Simon RP (1987) Kynurenate inhibition of cell excitation decreases stroke size and deficits. Ann Neurol 22:730-734.

Gill R, Foster A, Woodruff G (1987a) Systemic administration of MK-801 protects against ischemia-induced hippocampal neurodegeneration in the gerbil. J Neurosci 7:3345-3349.

Gill R, Foster A, Woodruff G (1987b) Systemic administration of MK-801 protects against ischemic neuropathology in rats. Br J Pharm 91:311.

Ginsberg MD (1981) Local brain blood flow-metabolism interrelationships in an expcrimental model of diffuse cerebral ischemia. In: Cerebral vascular disease 3 (Meyer JS, Llechner H, Reivich M, Ott EO, eds), Proceedings of the Tenth International Salzberg Conference, pp 195-200. Amsterdam: Excerpta Medica.

Hagberg H, Lehmann A, Sandberg M, Nystrom B, Jacobson I, Hamberger A (1985) Ischemia-induced shift of inhibition and excitatory amino acids from intra- to extracellular compartments. J Cereb Blood Flow Metab 5:413-419.

Jensen M, Auer $\mathbf{R}$ (1988) Ketamine fails to protect against ischemic neuronal necrosis in the rat. Br J Anaesth 61:206-210.

Jensen M, Auer R (1989) Intraventricular infusion of 2-amino-7phosphonoheptanoate (APH) mitigates ischemic brain damage. Neurol Res 11:37-40. 
Jorgensen M, Dicmer N (1982) Selective neuron loss after cerebral ischemia in the rat: possible role of transmitter glutamate. Acta Neurol Scan 66:536-546.

Kaplan B, Pulsinelli W (1989) Energy metabolites in the ischemic penumbra. Soc Neurosci Abst 15:855.

Kirino T (1982) Delayed neuronal death in the gerbil hippocampus following ischemia. Brain Res 237:57-69.

Kirino T, Tamura A, Sano K (1984) Delayed neuronal death in the rat hippocampus following transient forebrain ischemia. Acta Neuropath 64:139-147.

Lanier W, Perkins W, Karlsson B, Milde J, Scheithauer B, Sherman G, Michenfelder J (1990) The effects of dizocilipine maleate (MK-801), an antagonist of the $N$-methyl-D-aspartate receptor, on neurologic recovery and histopathology following complete cerebral ischemia in primates. J Cereb Blood Flow Mctab 10:252-261.

Mangano R, Schwarcz R (1983) Chronic infusion of endogenous excitatory amino acids into rat striatum and hippocampus. Brain Res Bull 10:47-51.

Marcoux F, Goodrich J, Dominick M (1988) Ketamine prevents ischemic neuronal injury. Brain Res 452:329-335.

McDonald J, Silverstein F, Johnston M (1987) MK-801 protects the neonatal brain from hypoxic-ischemic damage. Europ J Pharm 140: 359-361.

Meldrum B (1981) Metabolic effects of prolonged epileptic seizures and the causation of epileptic brain damage. In: Metabolic disorders of the nervous system. (Rose F, ed), pp 175-187. Iondon: Pitman.

Michenfelder J, Lainer W, Scheithauer B, Perkins W, Shearman G, Milde J (1989) Evaluation of the glutamate antagonist dizocilipine maleate (MK-801) on the ncurologic outcome in a canine model of complete cerebral ischemia: correlation with hippocampal histopathology. Brain Res 481:228-234.

Monaghan D, Cotman C (1985) Distribution of $N$-methyl-w-aspartate sensitive ${ }^{3} \mathrm{H}$-glutamate-binding sites in rat brain. Neurosci 5:29092919.

Olney JW (1978) Neurotoxicity of excitatory amino acids. In: Kainic acid as a tool in neurobiology (McGeer EG, Olney JW, McGeer PL, eds), pp 37-70. New York: Raven.

Olney J, Ikonomidou C, Mosinger J, Frierdich G (1989a) MK-801 prevents hypobaric-ischemic neuronal degeneration in infant rat brain. J Neurosci 9:1701-1704.

Olney JW, Labruyere J, Price M (1989b) Pathological changes induced in cerebrocortical neurons by phencyclidine and related drugs. Science 244:1360-1362.

Olney J, Labruyere J, Price M (1990) Phencyclidine, dizocilipine, and cerebrocortical neurons. Science 247:221.

Ozyurt E, Graham D, Woodruff G, McCulloch J (1988) Protective effect of the glutamate antagonist, MK-801 in focal cerebral ischemia in the cat. J Cereb Blood Flow Metab 8:138-143.

Park C, Nehls B, Graham D, Teasdale G, McCulloch J (1988) The glutamate antagonist MK-801 reduces focal ischemic brain damage in the rat. Ann Neurol 24:543-551.

Petito C, Feldmann E, Pulsinelli W, Plum F (1987) Delayed hippocampal arrest in humans following cardiorespiratory arrest. Neurology $37: 1281-1286$.

Pulsinelli W, Buchan A (1988) The four-vessel occlusion rat model: methods for complete occlusion of vertebral arteries and control of collateral circulation. Stroke 19:913-914.

Pulsinelli WA, Brierley JB (1979) A new model of bilateral hemispheric ischemia in the unanesthetized rat. Stroke 10:267-272.

Pulsinelli W, Duffy T (1983) Regional energy balance in rat brain after transient forebrain ischemia. J Neurochem 40:1500-1503.

Pulsinelli W, Brierley J, Plum F (1982a) Temporal profile of neuronal damage in a model of transient forebrain ischemia. Ann Neurol 11: 491-498.

Pulsinelli WA, Levy DE, Duffy TE (1982b) Regional cerebral blood flow and glucose metabolism following transient forebrain ischemia. Ann Neurol 11:499-509.

Rod M, Auer R (1989) Pre- and post-ischemic administration of di- zocilpine (MK-801) reduces cerebral necrosis in the rat. Can J Neurol Sci 16:340-344.

Rothman S (1985) The neurotoxicity of excitatory amino acids is produced by passive chloride influx. Neuro Sci 5:1483-1489.

Rothman SM, Olney JW (1986) Glutamate and the pathophysiology of hypoxic-ischemic brain damage. Ann Neurol 19:105-111.

Sauer D, Nuglisch J, Rossberg C, Mennel H-D, Beck T, Bielenberg G, Kriegelstein J (1988) Phencyclidine reduces postischemic neuronal necrosis in rat hippocampus without changing blood flow. Neurosci Lett 91:327-332.

Schmidt-Kastner R, Paschen W, Grosse Ophoff B, Hossman K-A (1989) A modified 4-vessel occlusion model for inducing incomplete forebrain ischemia in rats. Stroke 20:938-946.

Selman W, VanDerVeer C, Whittingham T, LaManna J, Lust W, Ratcheson R (1987) Visually defined zones of focal ischemia in the rat brain. Neurosurgery 21:825-830.

Siesjo B, Bengtsson F (1989) Calcium fluxes, calcium antagonists, and calcium-related pathology in brain ischemia, hypoglycemia, and spreading depression: a unifying hypothesis. J Cereb Blood Flow Metab 9:127-140.

Simon R, Swan J, Griffith T, Meldrum B (1984) Blockade of $N$-methyl$D$-aspartate receptors may protect against ischemic damage in the brain. Science 226:850-852.

Smith M-L, Auer RN, Siesjo BK (1984a) The density and distribution of ischemic brain injury in the rat following 2-10 min of forebrain ischemia. Acta Neuropathol (Berl) 64:319-332.

Smith M-L, Bendek G, Dahlgren N, Rosen I, Wieloch T, Siesjo BK (1984b) Models for studying long-term recovery following forebrain ischemia in the rat. A 2-vessel occlusion model. Acta Neurol Scand 69:385-401.

Spielmeyer W (1925) Zur Pathogenes der ortlich elecktiven Gehirnveranerungen. $Z$ Neurol Psychiatr 99:756-777.

Steinberg G, Saleh J, Kunis D (1988) Delayed treatment with dextromethorphan and dextrorphan reduces cerebral damage after transient focal ischemia. Neurosci Lett 89:193-197.

Swan J, Meldrum B (1990) Protection by NMDA antagonists against selective cell loss following transient ischemia. J Cereb Blood Flow Metab 10:343-351.

Swan J, Evans M, Meldrum B (1988) Long-term development of selective neuronal loss and the mechanism of protection by 2 -amino7-phosphonoheptanoic acid in a rat model of incomplete forebrain ischemia. J Cereb Blood Flow Metab 8:64-78.

Todd N, Picozzi P, Crockard H, Ross Russell R (1986) Recirculation after cerebral ischemia. Simultaneous measurement of cerebral blood flow, brain edema, cerebrovascular permeability and cortical EEG in the rat. Acta Neurol Scanda 74:269-278.

Tyson GW, Teasdale GM, Graham DI, McCulloch J (1984) Focal cerebral ischemia in the rat: topography of hemodynamic and histopathological changes. Ann Neurol 15:559-567.

Volpe B, Pulsinelli W, Tribuna J, Davis H (1984) Behavioral performance of rats following transient forebrain ischemia. Stroke 15:558562.

Wieloch T, Gustafson I, Westerberg E (1988) Effects on non-competitive NMDA receptor antagonist MK-801 on ischemic and hypoglycemic brain damage. In: Neurology and neurobiology, frontiers of excitatory amino acid research (Turski L, Lehmann E, Cavalheiro E, eds), pp 715-722. New York: Liss.

Wieloch T, Gustafson I, Westerberg E (1989) The NMDA antagonist, MK-801, is cerebro-protective in situations where some energy production prevails but not under conditions of complete energy deprivation. J Cereb Blood Flow Metab (Suppl) 9:S6-S7.

Yoshida S, Abe K, Busto R, Watson B, Kogure K, Ginsberg M (1982) Influence of transient ischemia on lipid soluble anti-oxidants, free fatty acids and energy metabolites in rat brain. Brain Res 245:307316.

Zar J (1974) Biostatistical analysis. Englewood Cliffs, NJ: PrenticeHall. 